\title{
Chronic inflammation in the respiratory tract and ciliary dyskinesia
}

\author{
KATARZYNA GRZELA', WIOLETTA ZAGÓRSKA ${ }^{l}$, EWA JANKOWSKA-STEIFER ${ }^{2}$,TOMASZ GRZELA \\ ${ }^{1}$ Department of Paediatrics, Pneumonology and Allergology, Medical University of Warsaw, Poland \\ 2Department of Histology and Embryology, Medical University of Warsaw, Poland
}

\begin{abstract}
The respiratory tract may be affected by various biological or chemical factors, which induce the inflammatory reaction in mucosa and submucosa. Depending on its severity, the inflammation may result in transient disability or a permanent damage of affected tissue. Usually, it is accompanied by various morphological and functional changes in epithelium, including impairment in ciliogenesis, the process of formation and regeneration of cilia. In this review authors focused on the influence of various intrinsic and external inflammation-related factors on a cilia structure and function, and their role in ciliary dyskinesia. Furthermore, some clinical and diagnostic aspects of the ciliary dyskinesia were also discussed.
\end{abstract}

Key words: chronic inflammation, respiratory tract, ciliogenesis, ciliary dyskinesia.

(Centr Eur J Immunol 2013; 38 (1): 122-128)

\section{Introduction}

Various detrimental factors may affect the respiratory tract. They include biological agents: bacteria, fungi, viruses or allergens, but also chemical and physical constituents of air pollution, with highly toxic chemical compounds of tobacco smoke. All of those factors may engage mechanisms of both, innate and acquired immunity $[1,2]$. Despite diverse characters of mentioned factors, both mechanisms lead to a development of inflammatory reaction, which involves mucosa and submucosa of the airway system. However, in case of any problem with regulation of immune response, or at a permanent exposure to the damaging agents, the first defense line of the innate immunity may fail [3]. This condition may predispose to the conversion of acute inflammatory reaction into its chronic form.

\section{Inflammation and epithelium}

Although the main role of immune response should be the elimination of the trigger - pathogen or inducing factor, nevertheless, it also may affect surrounding tissues. The inflammatory reaction, depending on its severity and duration, may result in transient disability, or in worse cases, permanent damage of affected tissues [4]. In respira- tory tract, the mild inflammatory response will modify the composition and biophysical properties of mucus and increases the number of mucosa-infiltrating leukocytes. Usually, it is also accompanied by various morphological and functional changes in epithelium [5]. The enhanced intensity of inflammatory reaction in mucosal and submucosal connective tissue may lead to its remodeling and fibrosis.

Numerous studies with the use of in vitro cultured ciliated epithelium and ex vivo observations have shown, that various proinflammatory factors may affect the process of formation and regeneration of cilia, known as ciliogenesis [6-8]. Therefore, at the beginning, epithelial cells may reveal some reversible abnormalities in structure and function of their cilia. From practical point of view it may be clinically relevant as potential target of various therapeutic approaches, hence, in this review authors would focus mainly on this issue. Noteworthy, further aggravation of epithelial cells results in complete loss of their cilia and reprogramming of epithelial precursor/stem cells differentiation from mucus-secreting, pseudostratified cuboidal, into the squamous stratified epithelium. This change is known as squamous epithelial metaplasia [9]. The prolonged exposure to the irritant, e.g. cigarette smoke, while

Correspondence: Katarzyna Grzela, MD, PhD, Department of Paediatrics, Pneumonology and Allergology, Medical University of Warsaw, Dzialdowska 1, 01-184 Warsaw, Poland 
affecting epithelial stem cells, may further result in neoplastic transformation of epithelium $[10,11]$.

\section{Cilia}

Normal cilia are present on ciliated epithelia of respiratory system and oviduct, or as a single flagellum in spermatozoon (sperm cell). They are composed of axoneme core, which is covered by phospholipid bilayer of cell membrane. The axoneme is formed by two central microtubule singlets surrounded by the ring of nine microtubule doublets with attached accessory proteins (Fig. 1A) [2, 12, 13]. This normal structure is usually described as " $9+2$ " pattern. The proximal part of cilium core, which is anchored in cytoplasm, is formed by a ring of nine microtubule triplets, without central microtubules, and is known as the basal body (Fig. 1B, C, respectively). The transition zone between the basal body and the axoneme was recognized as the docking place for numerous proteins, including dyneins, kinesin and many others, which participate in bidirectional transport within the cilium [13, 14]. The normal cilia display coordinated, wave-like, two-phase movement with a mean frequency of approx. $12 \mathrm{~Hz}$. This movement enables the mucus transport with the average speed up to $30 \mathrm{~cm} / \mathrm{h}[2,12,15]$.

Interestingly, besides previously mentioned motile cilia, majority of cells in human body contain on their apical surface the single immotile cilium, known as primary cilium $[13,14,16]$. Primary cilia are considered as cellular sensors for physical and biochemical extracellular signals. Their structure is described as " $9+0$ " pattern, that corresponds to nine microtubule doublets, without central singlets [14].

\section{Ciliogenesis}

The formation and regeneration of cilia is controlled in a course of ciliogenesis. Usually, ciliogenesis is described as a process divided into four stages: 1) duplication of centrioles; 2) migration of centrioles to the apical cell surface and formation of basal bodies; 3) elongation of microtubules to form the cilium core, the axoneme; and 4) formation of accessory structures of basal bodies [13, 17].

Although the ciliogenesis is considered as strictly controlled event within the cell, nevertheless, it is not free of various errors. Abnormal cilia may be repaired or fall off from the epithelium. Therefore, under normal conditions they are encountered in mature ciliated cells rather rarely. However, as mentioned previously, the prolonged stress may result in impaired ciliogenesis and formation of abnormal cilia, including compound and/or swollen cilia [16, 17].

The compound cilia are those, which contain multiple axonemal structures enclosed by a common membrane of phospholipid bilayer. Depending on the arrangement of the axonemes, compound cilia are divided into two types: the type 1 , composed of densely embedded axonemes, that is named the adhesive type, and the type 2, containing loosely and randomly arranged axonemes, which is known as the bulging type [17].

Swollen cilia display balloon-like enlargements with excessive cytoplasmic matrix in various parts of the ciliary shafts. Usually, the structure of axoneme retains the normal " $9+2$ " pattern, nevertheless, in swollen parts of cilia the microtubules may be dislocated [17]. The enlargements are formed during cilia protruding by accompanying the apical cytoplasmic matrix. The matrix of swollen parts may con-
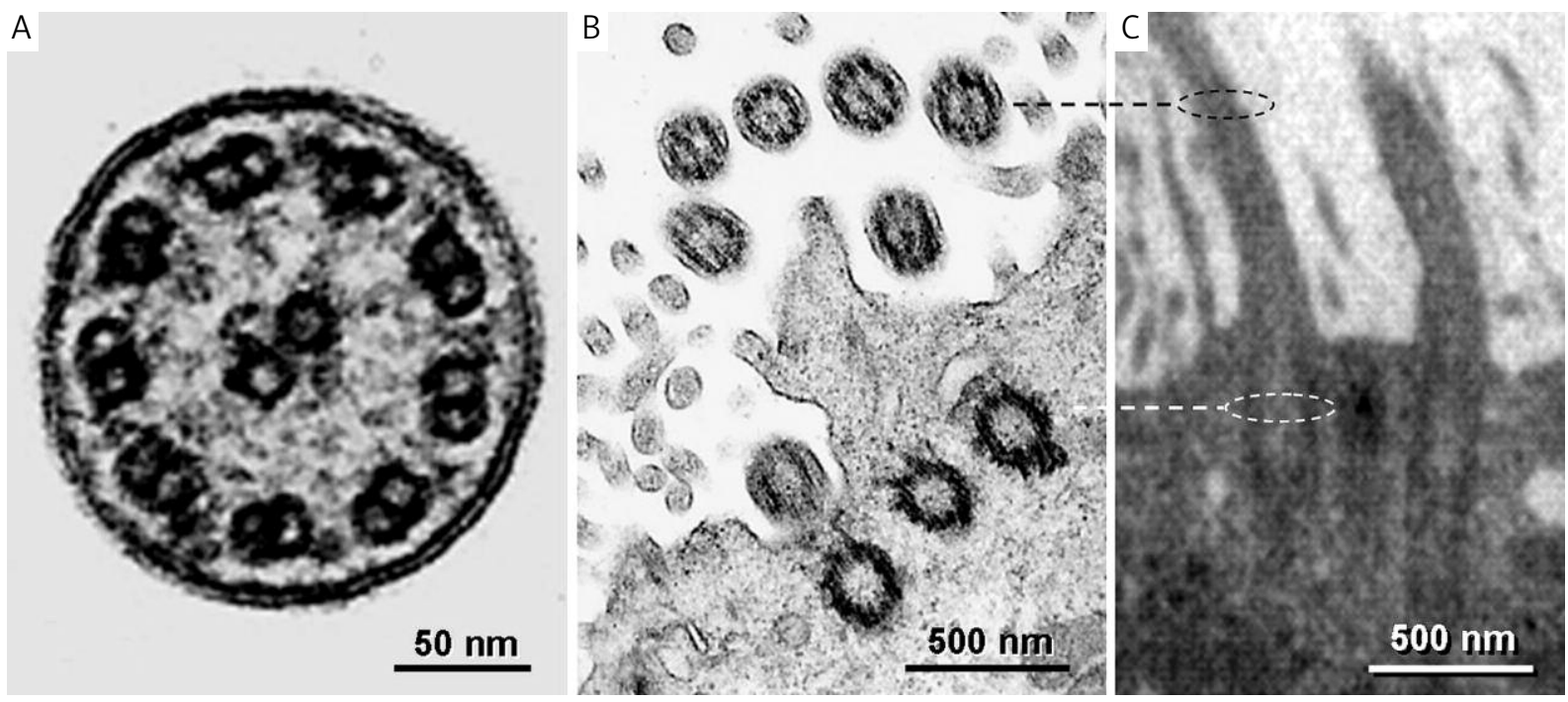

Fig. 1. Ultrastructure of ciliated epithelial cell, pictures from transmission electron microscope. Cross-section of mature cilium with " $9+2$ " axoneme pattern (A). Magnification approx. 120 000x. Cross-section (B) and longitudinal section (C) of mature cilium. Corresponding parts of cilium were marked with dashed lines. Note the microtubule triplets, without central singlets, in basal bodies. Magnification approx. 20 000× 
tain tubulin or other axoneme components. Most often, these portions disappear from the shafts, when the cilia grow and elongate.

\section{Ciliary dyskinesia}

The disturbances in ciliogenesis, leading to impairment in cilia structure and function may result from ciliopathy, the large and heterogenous group of genetically determined diseases, including Kartagener syndrome, polycystic kidney disease, Alström syndrome, Bardet-Biedl syndrome, nephronophthisis, and many others $[14,16,18]$. On the other hand, the abnormal function of cilia, commonly known as the ciliary dyskinesia, may be secondary to various problems in cilia formation and elongation. Depending on the origin of these impairments, ciliary dyskinesia may be divided into a primary and secondary form $[12,19]$.

\section{Primary ciliary dyskinesia}

The primary ciliary dyskinesia (PCD), also known as Kartagener syndrome, is an inherited, genetically determined disease, with the estimated incidence 1 in 32000 , up to as high, as 1 in 15000 [20, 21]. Primary ciliary dyskinesia is associated with occurrence of several characteristic symptoms, among them - an increased susceptibility to recurrent infections of respiratory tract. However, these symptoms result from impaired movement of cilia, which is secondary to various abnormalities in cilia structure.

Primary ciliary dyskinesia is caused by diverse mutations, predominantly (approx. 80-90\% of all PCD cases) in genes encoding for dynein motor proteins. Interestingly, the most frequent (approx. 38\% of all PCD patients) are two mutations of dynein genes, DNAI1 and DNAH5 [22, 23]. Several other PCD-associated mutations described so far include: DNAH11, TXNDC3, DNAI2, KTU, RSPH4A, RSPH9, LRRC50, etc. [12, 23-25].

\section{Secondary ciliary dyskinesia}

In contrast to PCD, the mechanism of development of secondary ciliary dyskinesia (SCD) represents an opposite order. The intrinsic factors or external triggers induce inflammatory reaction in mucosa of the respiratory tract. Then, chronic stimulation/irritation of epithelial cells may lead to loss of already formed cilia and impairs the ciliogenesis. As the result, may appear atypical, de novo growing cilia, which reveal the abnormal movement pattern $[12,17,19]$. Obviously, the impaired cilia movement significantly increases the susceptibility to further infection [2]. Therefore, the SCD is much more frequent than PCD, since practically it may develop in each individual exposed to respective stimuli $[26,27]$.

\section{"Modifiers" of cilia movement}

The key players of inflammatory reaction - macrophages, neutrophils, eosinophils, lymphocytes and epithelial cells express and release a cocktail of cytokines, which regulate the immune response. On the other hand, these cytokines may also influence the activity of cilia. It was proven, that IL-1 $\beta$ and tumor necrosis factor (TNF) stimulated the cilia motility [28], whereas IL-6, IL-8 and IL-13 significantly decreased the frequency of cilia movement [29-32]. In addition to the impaired cilia motility, IL-13 induced mucous cells hyperplasia and hypersecretion of mucus, thus, further affecting the mucociliary clearance [32].

Besides the cytokines, it was found that the cilia movement may also be influenced by $\mathrm{pH}$ and temperature. The low values of $\mathrm{pH}$ or temperature decreased frequency of cilia beats. Oppositely, higher $\mathrm{pH}$ or increased temperature resulted in increase of ciliary motility $[33,34]$. Likewise, the various medication may modify the cilia activity. It was found that decreased cilia movement may result from topical use of steroids [35], some antibiotics, antimycotics, or antiseptics [36].

On the other hand, the increase of cilia motility may be achieved by application of prostacyclin [37], a neuromodulatory peptide - substance P (SP) [38], or methacholine, a non-selective agonist of cholinergic (muscarinic) receptors [39]. Also, it has been proven that cilia beats frequency may increase following the activation of adrenergic and purinergic receptors $[15,40]$. Furthermore, numerous other external factors may influence the cilia motility and ciliogenesis in both, direct and indirect manner. Among a broad range of air pollution constituents, an important position have toxic components of tobacco smoke [27, 41, 42]. In addition to well documented negative direct influence on a structure and motility of cilia it was proven that tobacco smoke components decrease the cilia number [43, 44], and affect their regeneration [45]. The negative action of tobacco smoke-related factors on cilia and ciliogenesis may involve the impaired expression of several regulatory/proinflammatory cytokines in epithelial cells. It has been demonstrated that acrolein from tobacco smoke decreased expression of chemokine IL- 8 and defensin $\beta-2$ in epithelial cells [46]. Moreover, mentioned tobacco smoke-related factors stimulated secretion of mucins with simultaneous decrease of mucus hydration, thus resulting in increased viscosity and density of mucus [47, 48].

Also, several bacterial toxins have been proven to affect cilia motility. It was found that Streptococcus pneumoniae-derived pneumolysins and toxins of Haemophilus influenzae decreased ciliary beats frequency [49-51]. Similar influence on cilia activity may also reveal some toxins of other common pathogens: Pseudomonas aeruginosa and Staphylococcus aureus, as well as some viruses responsible for respiratory tract infections [52]. Through cilia immobilization, or their loss, that is associated with impairment of mucociliary clearance, the mentioned toxins facilitate bacterial colonization of mucus and support the progression of inflammatory process towards the chronic form [50, 53]. 


\section{Recognition of ciliary dyskinesia}

As mentioned previously, the secondary form of ciliary dyskinesia may affect potentially each individual. However, in contrast to PCD, usually it is reversible $[8,54]$. Therefore, a proper recognition of ciliary dyskinesia seems to be crucial for clinical prognosis, especially in young children. The differential diagnostics concerns three main approaches - the assessment of cilia function, the analysis of their morphology, and detection of presumable genetic abnormalities (Fig. 2) [12, 55]. Moreover, since patients with PCD, but not those with SCD, reveal low concentration of nitric oxide (NO) in exhaled air, this method may also be helpful in diagnostics of ciliary dyskinesia $[56,57]$.

\section{The assessment of cilia morphology}

The morphological assessment concerns the analysis of cilia ultrastructure using transmission electron microscope (TEM), which is still considered as the "golden standard" [58-60]. The main problem in this approach is a sufficient amount of material, with enough number of cilia for microscopic evaluation. Therefore, since this method does not clarify the origin of ciliopathy, usually it engages the further diagnostic techniques.

Most recently, the cilia morphology and, in some extend, their biochemical composition may be assessed with the use of laser scanning confocal microscope (LSCM) [14, 16].

\section{The assessment of cilia function}

The analysis of cilia function may be performed using both, in vivo and in vitro tests. The in vivo methods enable the assessment of mucociliary clearance by monitoring the effectiveness of mucus transport after application of some tracer, e.g. ${ }^{99 \mathrm{~m}} \mathrm{Tc}$-labeled albumin, or formerly - saccharin $[55,62]$. These methods, although highly sensitive in detection of cilia function abnormalities, do not allow to discriminate between primary and secondary dyskinesia. The in vitro tests concern the direct assessment of cilia motility in mucosal bioptates or cytological specimens of nasal epithelial brushing $[63,64]$. The analysis requires the use of phase-contrast microscope with high-speed camera and focuses on cilia beats frequency and the pattern of their movement $[59,61]$. The coordinated movement with normal pattern allows to reject the suspicion of dyskinesia. However, if abnormal, this finding has to be verified with additional tests.

\section{Genetic assessment}

The identification of any mentioned previously, known mutation in genes encoding for axoneme components allows the recognition of primary form of the ciliary dyskinesia $[23,25,59]$. However, the negative result of genetic assessment, although rather suggests the secondary dyskinesia, may not exclude univocally the possibility of PCD. It is due

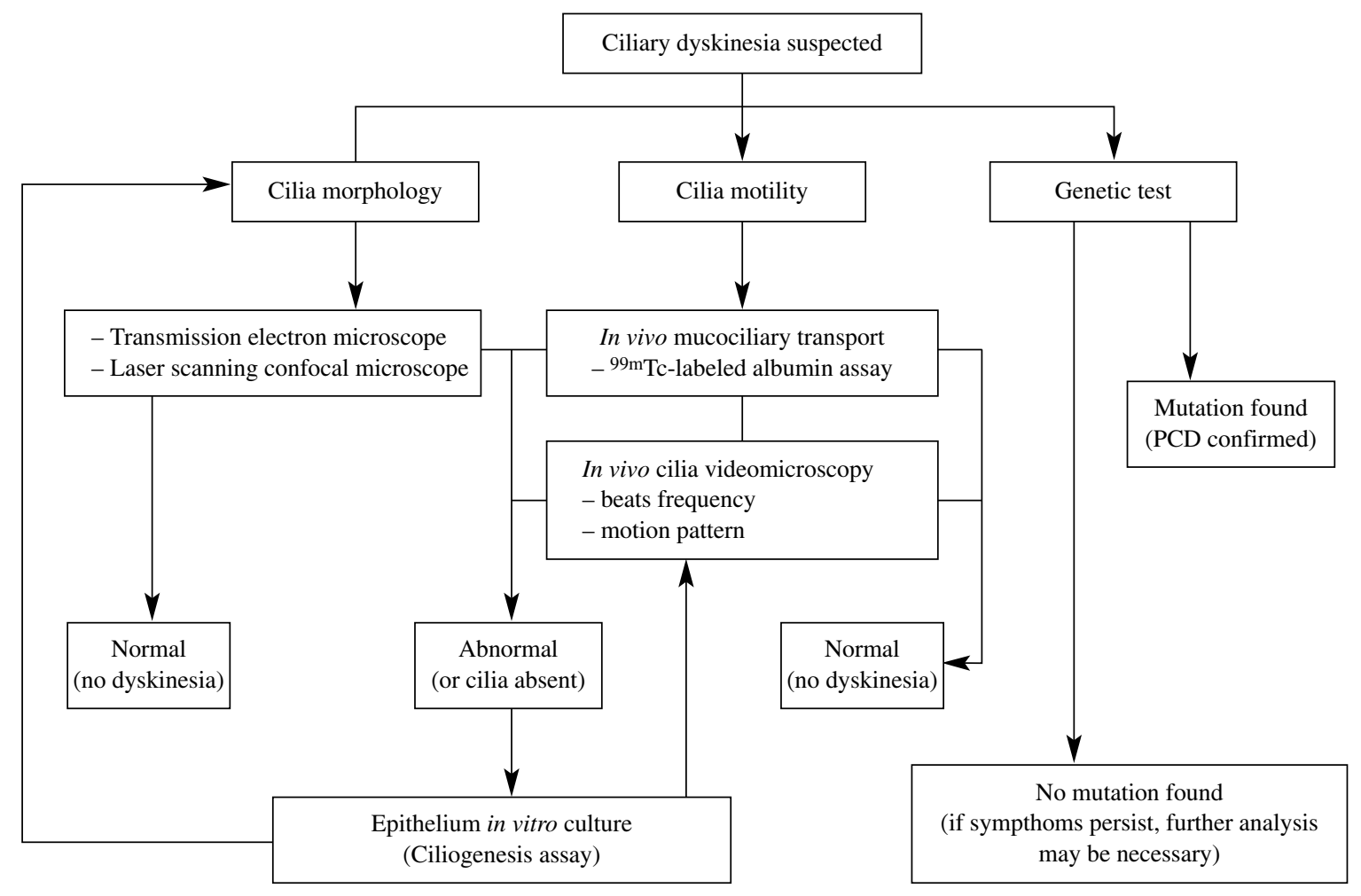

Fig. 2. The flowchart of the proposed algorithm for diagnostic of ciliary dyskinesia (see detailed description in text) 

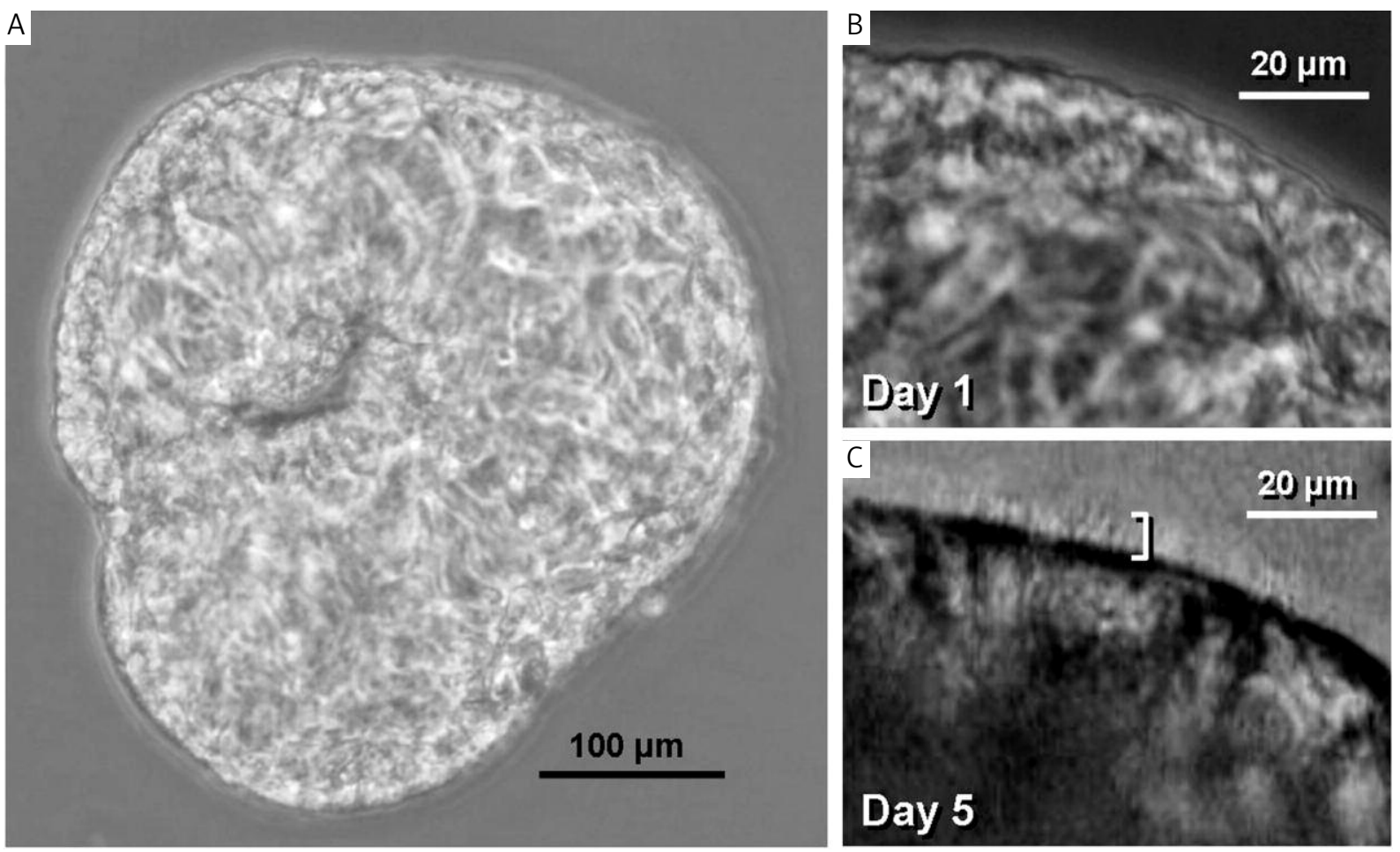

Fig. 3. Ciliogenesis in vitro. Pictures from phase-contrast microscope show the spheroid aggregate of epithelium, which was maintained in dynamic 3D culture. The whole spheroid at the 300× magnification (A). The same spheroid at the high magnification (approx. 1000×), seen in day 1 (B), and day 5 (C), with new cilia growing on its surface (marked with the square bracket - "]").

to a fact, that the number of till now identified, PCD-related mutations is still increasing [23,59]. Therefore, in case of recurrent symptoms of dyskinesia, which still exist despite elimination, or avoidance of potential trigger, it is recommended to perform further investigation. This may be especially important in individuals with abnormal results of other assays (including TEM and direct videomicroscopy) and/or in vitro culture.

\section{In vitro culture - ciliogenesis test}

As shown on a flowchart, in case of any problems with assessment of cilia morphology, or uncertain results of direct evaluation of cilia motility, a further diagnosis may require the use of in vitro culture method with the ciliogenesis test $[6,65]$. Small biopsies of nasal or tracheal mucosa are microdissected and digested with pronase, to separate epithelium from a connective tissue. Alternatively, the epithelium specimens, collected with the use of diagnostic brush may be used instead, without the necessity of a treatment with protease. Epithelial sheets or dispersed epithelial cells are then incubated in culture medium, in humidified atmosphere, with $5 \% \mathrm{CO}_{2}$, at $37^{\circ} \mathrm{C}$. Some authors recommend the use of air-liquid interphase (ALI) method, as the maximally mimicking the physiological conditions [66]. The others prefer the dynamic three-dimentional in vitro culture in suspension [65, 67]. In the last method epithelial aggregates spontaneously form the spheroid-like shapes (Fig. 3A). After several days of culture in mentioned conditions, the cilia start to regenerate (Fig. 3B, C), thus allowing their further repetitive analysis.

\section{Concluding remarks}

Chronic inflammatory reaction in the respiratory tract may be associated with some defects in the morphology and function of pseudostratified ciliated epithelial cells. It is noteworthy, that the mentioned abnormalities, commonly known as ciliary dyskinesias, may represent various origin, depending on their molecular background. Thus, the genetically determined, irreversible aberrations in cilia structure, represented by primary ciliary dyskinesia, affect the mucociliary clearance and increase susceptibility to infection. On the other hand, the infection itself may result in impaired cilia function, that is associated with usually reversible condition, described as the secondary ciliary dyskinesia. Due to extremely different clinical prognosis, the proper identification of ciliary dyskinesia is of great importance. Despite the use of various methods, including genetical analysis, an univocal identification is not always possible. Recently, the increasing role play methods based 
on in vitro cultures of epithelial cells and analysis of de novo formed cilia. However, due to limited experience, this approach still requires further studies.

\section{The authors declare no conflict of interest.}

\section{References}

1. Żukiewicz-Sobczak W, Cholewa G, Krasowska E, et al. (2012): Pathogenic fungi in the work environment of organic and conventional farmers. Postep Derm Alergol 29: 256-262.

2. Grzela K, Zagórska W, Grzela T (2012): Mechanisms of the innate immunity in the respiratory system. Centr Eur J Immunol 37: 280-285.

3. Ooi E, Psaltis AJ, Witterick I, et al. (2010): Innate immunity. Otolaryngol Clin N Am 43: 473-487.

4. Proud D, Leigh R (2011): Epithelial cells and airway diseases. Immunol Rev 242: 186-204.

5. Thomas B, Rutman A, O'Callaghan C (2009): Disrupted ciliated epithelium shows slower ciliary beat frequency and increased dyskinesia. Eur Respir J 34: 401-404.

6. Wong JY, Rutman A, O'Callaghan C (2005): Recovery of the ciliated epithelium following acute bronchiolitis in infancy. Thorax 60: 582-587.

7. Jorissen M, Willems T (2000): Success rates of respiratory epithelial cell culture techniques with ciliogenesis for diagnosing primary ciliary dyskinesia. Acta Otorhino-laryngol Belg 54: 357-365.

8. Jorissen M, Willems T, Van der Schueren B, Verbeken E (2000): Secondary ciliary dyskinesia is absent after ciliogenesis in culture. Acta Otorhinolaryngol Belg 54: 333-342.

9. Bolton SJ, Pinnion K, Oreffo V, et al. (2009): Characterisation of the proximal airway squamous metaplasia induced by chronic tobacco smoke exposure in spontaneously hypertensive rats. Respir Res 10: 118.

10. Tamashiro E, Xiong G, Anselmo-Lima WT, et al. (2009): Cigarette smoke exposure impairs respiratory epithelial ciliogenesis. Am J Rhinol Allergy 23: 117-122.

11. Verra F, Escudier E, Lebargy F, et al. (1995): Ciliary abnormalities in bronchial epithelium of smokers, ex-smokers, and nonsmokers. Am J Respir Crit Care Med 151: 630-634.

12. Kulus M, Grzela K (2009): Diagnostyka zaburzeń ruchomości rzęsek nabłonka oddechowego. In: Diagnostyka rynologiczna. Krzeski A (ed.). Wydawnictwo Medycyna Praktyczna, Kraków, 97-102.

13. Ishikawa H, Marshall WF (2011): Ciliogenesis: building the cell's antenna. Nat Rev Mol Cell Biol 12: 222-234.

14. Fliegauf M, Benzing T, Omran H (2007): When cilia go bad: cilia defects and ciliopathies. Nat Rev Mol Cell Biol 8: 880-893.

15. Salathe M (2007): Regulation of mammalian ciliary beating. Annu Rev Physiol 69: 401-422.

16. Adams M, Smith UM, Logan CV, Johnson CA (2008): Recent advances in the molecular pathology, cell biology and genetics of ciliopathies. J Med Genet 45: 257-267.

17. Hagiwara H, Ohwada N, Aoki T, Takata K (2000): Ciliogenesis and ciliary abnormalities. Med Electron Microsc 33: 109-114.

18. Marshall WF (2008): The cell biological basis of ciliary disease. J Cell Biol 180: 17-21.
19. Armengot M, Milara J, Mata M, et al. (2010): Cilia motility and structure in primary and secondary ciliary dyskinesia. Am J Rhinol Allergy 24: 175-180.

20. Chodhari R, Mitchison HM, Meeks M (2004): Cilia, primary cilia dyskinesia and molecular genetics. Paediatr Respir Rev 5: 69-76.

21. Bush A, Chodhari R, Collins N, et al. (2007): Primary ciliary dyskinesia: current state of the art. Arch Dis Child 92: 1136-1140.

22. Afzelius BA (2004): Cilia-related diseases. J Pathol 204: 470-477.

23. Zariwala MA, Knowles MR, Omran H (2007): Genetic defects in ciliary structure and function. Annu Rev Physiol 69: 423-450.

24. Morillas HN, Zariwala M, Knowles MR (2007): Genetic causes of bronchiectasis: primary ciliary dyskinesia. Respiration 74: 252-263.

25. Geremek M, Witt M (2004): Primary ciliary dyskinesia: genes, candidate genes and chromosomal regions. J Appl Genet 45: 347-361.

26. Jorissen M, Bertrand B, Eloy P (1997): Ciliary dyskinesia in the nose and paranasal sinuses. Acta Otorhinolaryngol Belg 51: 353-366.

27. Elliott MK, Sisson JH, Wyatt TA (2007): Effects of cigarette smoke and alcohol on ciliated tracheal epithelium and inflammatory cell recruitment. Am J Respir Cell Mol Biol 36: 452-459.

28. Jain B, Rubinstein I, Robbins RA, Sisson JH (1995): TNF-alpha and IL-1 beta upregulate nitric oxide-dependent ciliary motility in bovine airway epithelium. Am J Physiol 268: L911-917.

29. Papathanasiou A, Djahanbakhch O, Saridogan E, Lyons RA (2008): The effect of interleukin-6 on ciliary beat frequency in the human fallopian tube. Fertil Steril 90: 391-394.

30. Allen-Gipson DS, Romberger DJ, Forget MA, et al. (2004): IL-8 inhibits isoproterenol-stimulated ciliary beat frequency in bovine bronchial epithelial cells. J Aerosol Med 17: 107-115.

31. Shen JC, Chen B, Cohen NA (2012): Keratinocyte chemoattractant (interleukin-8) regulation of sinonasal cilia function in a murine model. Int Forum Allergy Rhinol 2: 75-79.

32. Laoukili J, Perret E, Willems T, et al. (2001): IL-13 alters mucociliary differentiation and ciliary beating of human respiratory epithelial cells. J Clin Invest 108: 1817-1824.

33. Sutto Z, Conner GE, Salathe M (2004): Regulation of human airway ciliary beat frequency by intracellular $\mathrm{pH}$. J Physiol 560: 519-532.

34. Mwimbi XK, Muimo R, Green MW, Mehta A (2003): Making human nasal cilia beat in the cold: a real time assay for cell signaling. Cell Signal 15: 395-402.

35. Hofmann T, Gugatschga M, Koidl B, Wolf G (2004): Influence of preservatives and topical steroids on ciliary beat frequency in vitro. Arch Otolaryngol Head Neck Surg 130: $440-445$.

36. Gosepath J, Grebneva N, Mossikhin S, Mann WJ (2002): Topical antibiotic, antifungal, and antiseptic solutions decrease ciliary activity in nasal respiratory cells. Am J Rhinol 16: 25-31.

37. Tamaoki J, Sakai S, Chiyotani A, et al. (1994): Effects of prostacyclin and beraprost on ciliary motility of rabbit airway epithelium. Pharmacology 48: 194-200.

38. Schlosser RJ, Czaja JM, Yang B, McCaffrey TV (1995): Signal transduction mechanisms in substance P-mediated ciliostimulation. Otolaryngol Head Neck Surg 113: 582-588.

39. Yang B, Schlosser RJ, McCaffrey TV (1997): Signal transduction pathways in modulation of ciliary beat frequency by methacholine. Ann Otol Rhinol Laryngol 106: 230-236. 
40. Lazarowski ER, Boucher RC (2009): Purinergic receptors in airway epithelia. Curr Opin Pharmacol 9: 262-267.

41. Verra F, Escudier E, Lebargy F, et al. (1995): Ciliary abnormalities in bronchial epithelium of smokers, ex-smokers, and nonsmokers. Am J Respir Crit Care Med 151: 630-634.

42. Leopold PL, O'Mahony MJ, Lian XJ, et al. (2009): Smoking is associated with shortened airway cilia. PLoS One 4: e8157.

43. Wanner A, Salathé M, O'Riordan TG (1996): Mucociliary clearance in the airways. Am J Respir Crit Care Med 154: 1868-1902.

44. Işik AC, Yardimci S, Guven C, et al. (2007): Morphologic alternation induced by short-term smoke exposure in rats. ORL J Othorhinolaryngol Relat Spec 69: 13-17.

45. Tamashiro E, Xiong G, Anselmo-Lima WT, et al. (2009): Cigarette smoke exposure impairs respiratory epithelial ciliogenesis. Am J Rhinol Allergy 23: 117-122.

46. Lee WK, Ramanathan M Jr, Spannhake EW, Lane AP (2007): The cigarette smoke component acrolein inhibits expression of the innate immune components IL-8 and human beta-defensin 2 by sinonasal epithelial cells. Am J Rhinol 21: 658-663.

47. Kreindler JL, Jackson AD, Kemp PA, et al. (2005): Inhibition of chloride secretion in human bronchial epithelial cells by cigarette smoke extract. Am J Physiol Lung Cell Mol Physiol 288: L894-L902.

48. Gensch E, Gallup M, Sucher A, et al. (2004): Tobacco smoke control of mucin production in lung cells requires oxygen radicals AP-1 and JNK. J Biol Chem 279: 39085-39093.

49. Feldman C, Anderson R, Cockeran R, et al. (2002): The effects of pneumolysin and hydrogen peroxide, alone and in combination, on human ciliated epithelium in vitro. Respir Med 96: 580-585.

50. St Geme JW 3rd (2000): The pathogenesis of nontypable Haemophilus influenzae otitis media. Vaccine 19: S41-S50.

51. Ferguson JL, McCaffrey TV, Kern EB, Martin WJ 2nd (1988): The effects of sinus bacteria on human ciliated nasal epithelium in vitro. Otolaryngol Head Neck Surg 98: 299-304.

52. Jones $N$ (2001): The nose and paranasal sinuses physiology and anatomy. Adv Drug Deliv Res 51: 5-19.

53. Majima Y, Sakakura Y, Matsubara T, Miyoshi Y (1986): Possible mechanisms of reduction of nasal mucociliary clearance in chronic sinusitis. Clin Otolaryngol Allied Sci 11: 55-60.

54. Bertrand B, Collet S, Eloy P, Rombaux P (2000): Secondary ciliary dyskinesia in upper respiratory tract. Acta Otorhinolaryngologica Belg 54: 309-316.

55. Jorissen M, Willems T, De Boeck K (2000): Diagnostic evaluation of mucociliary transport: from symptoms to coordinated ciliary activity after ciliogenesis in culture. Am J Rhinol 14: 345-352.

56. Pifferi M, Caramella D, Cangiotti AM, et al. (2007): Nasal nitric oxide in atypical primary ciliary dyskinesia. Chest 131 : 870-873.

57. Santamaria F, De Stefano S, Montella S, et al. (2008): Nasal nitric oxide assessment in primary ciliary dyskinesia using aspiration, exhalation, and humming. Med Sci Monit 14: CR80-85.

58. Bush A, Cole P, Hariri M, et al. (1998): Primary ciliary dyskinesia: diagnosis and standards of care. Eur Respir J 12: 982-988.

59. Barbato A, Frischer T, Kuehni CE, et al. (2009): Primary ciliary dyskinesia: a consensus statement on diagnostic and treatment approaches in children. Eur Respir J 34: 1264-1276.
60. Lie H, Ferkol T (2007): Primary ciliary dyskinesia: recent advances in pathogenesis, diagnosis and treatment. Drugs 67: 1883-1892.

61. Stannard WA, Chilvers MA, Rutman AR, et al. (2010): Diagnostic testing of patients suspected of primary ciliary dyskinesia. Am J Respir Crit Care Med 181: 307-314.

62. De Boeck K, Proesmans M, Mortelmans L, et al. (2005): Mucociliary transport using ${ }^{99 \mathrm{~m}} \mathrm{Tc}$-albumin colloid: a reliable screening test for primary ciliary dyskinesia. Thorax 60 : 414-417.

63. Caruso G, Gelardi M, Passali GC, de Santi MM (2007): Nasal scraping in diagnosing ciliary dyskinesia. Am J Rhinol 21: 702-705.

64. Mosler K, Coraux C, Fragaki K, et al. (2008): Feasibility of nasal epithelial brushing for the study of airway epithelial functions in CF infants. J Cyst Fibros 7: 44-53.

65. Jorissen M, Van der Schueren B, Van den Berghe H, Cassiman JJ (1989): The preservation and regeneration of cilia on human nasal epithelial cells cultured in vitro. Arch Otorhinolaryngol 246: 308-314.

66. Ross AJ, Dailey LA, Brighton LE, Devlin RB (2007): Transcriptional profiling of mucociliary differentiation in human airway epithelial cells. Am J Respir Cell Mol Biol 37: 169-185.

67. Willems T, Jorissen M (2004): Sequential monolayer-suspension culture of human airway epithelial cells. J Cyst Fibros 3: 53-54. 